\title{
La agresión \\ en el contexto de la etología y la antropología*
}

\author{
Aggressiveness in the ethology and anthropology \\ context*
}

\section{A agressão no contexto da etologia e a antropologia*}

\section{Juan Alejandro Brando** Argentina}

Recibido el 12 de septiembre de 2012, aceptado el 24 de enero 2013

** Este trabajo es parte de la investigación conducente al doctorado en filosofía por la Universidad Nacional de Lanús, la cual fue parcialmente financiada por una beca de postgrado tipo II del Consejo Nacional de Investigaciones Científicas y Técnicas de Argentina. La citada investigación pretende evaluar críticamente las averiguaciones de la etología, o ciencia del comportamiento animal, con respecto a los orígenes de la agresividad, en cuanto pretenden ser referidos a la elucidación de la agresión humana.

* Profesor en filosofía por la Universidad Nacional de Mar del Plata. Correo electrónico: alejandrobrando@yahoo.com.ar 


\section{Resumen}

Objetivo: caracterizar las posiciones de la etología humana en la versión de EiblEbesfeld y confrontarla con algunas premisas de la antropología cultural, en lo concerniente al pensamiento sobre la agresión, enfatizando los puntos en común que puedan reconocerse en ambas perspectivas Metodología: consiste en evaluar un intento de explicación del fenómeno de la agresividad humana, conceptualizada a partir de criterios funcionales. En principio, se trata de reconstruir los argumentos de la etología humana, para después, contrastarlos con los esgrimidos por cierta tendencia predominante en la antropología cultural. Resultados: hay, en general, dos posiciones antropológicas discrepantes: una que considera a la especie humana determinada mayormente por la evolución biológica, y otra que considera al hombre influido principalmente por su adaptación al ambiente. No obstante, pueden encontrarse puntos de comunión entre la perspectiva innatista y la culturalista, que servirían de apoyo a una caracterización comprehensiva de la agresión. Conclusiones: es insoslayable, a la hora de pensar en los posibles orígenes de la agresión humana, la aceptación de las implicaciones del aprendizaje social. Es evidente una "saturación" de ciertos conceptos comunes a las dos posturas, lo que demuestra que ambas caracterizaciones de la agresión están más próximas teóricamente de lo que podía suponerse prima facie.

Palabras claves: agresión, etología, antropología, moralidad

\section{Abstract}

Objective: to characterize the human ethology from Eibl-Eibesfeld's perspective and to contrast it with some premises of cultural anthropology, in regard to aggressiveness, by emphasizing the aspects common to both perspectives. Methodology: it consists of evaluating an attempt to explain the phenomenon of human aggressiveness that is conceptualized from some functional criteria. Firstly, some arguments of human ethology are established and then, they are compared to the ones used by the dominant tendency in cultural anthropology. Results: there are two dissenting anthropological perspectives: one considers the 
human species are largely determined by biological evolution, and the other one considers the mankind is mainly influenced by his adaptation to the environment. However, both perspectives have common aspects between the innatist and cultural perspectives. These would lead to a comprehensive characterization of aggressiveness. Conclusions: When thinking of the possible causes of aggressiveness, it is necessary to consider the acceptance of the implications of social learning. There is a clear "saturation" of certain concepts common to both perspectives, which shows that both characterizations of aggressiveness are theoretically closer than it was assumed prima facie.

Keywords: aggressiveness, ethology, enthropology, morality.

\section{Resumo}

Objetivo: caracterizar as posições da etologia humana na versão de Eibl-Ebesfeld e confrontar lá com algumas premissas da antropologia cultural, no concernente ao pensamento sobre a agressão, enfatizando os pontos em comum que podem reconhecer se em ambas as perspectivas. Metodologia: Consiste em avaliar um tento de explicação do fenômeno da agressividade humana, conceitualização a partir de critérios funcionais. Em principio, trata se de reconstruir os argumentos da etologia humana, para depois, contrastá-los com os esgrimidos por certa tendência predominante na antropologia cultural. Resultados: Há, em geral, duas posições antropológicas discrepantes: uma que considera a espécie humana determinada, maiormente pela evolução biológica, e outra que considera ao homem influído principalmente pela sua adaptação ao ambiente. Não obstante, podem encontrar se pontos de comunhão entre a perspectiva inatista e o culturalismo, que serviram de apoio a uma caracterização compreensiva da agressão. Conclusões: é inescapável, à hora de pensar nos possíveis origens da agressão humana, a aceitação das implicações da aprendizagem social. É evidente uma "saturação" de certos conceitos comunes às duas posturas, o que demonstra que ambas as caracterizações da agressão estão mais próximas teoricamente do que podia supor se prima facie.

Palavras chaves: agressão, etologia, antropologia, moralidade. 


\section{Introducción}

En las disciplinas que tienen pertinencia en los estudios sobre la agresión, suele admitirse que la naturaleza humana posee un principio natural de agresividad que le es inherente. Este convencimiento se ha nutrido de numerosas e interesantes investigaciones de la sociología de los animales superiores, que aspiran a esclarecer algunos aspectos de la conducta humana.

La aparición del importante libro de Konrad Lorenz Sobre la agresión: el pretendido mal (Lorenz, 1971) despertó un singular interés al introducir, en los debates acerca de la agresión y la violencia, las hipótesis y conclusiones de las ciencias del comportamiento animal. Lorenz ha resaltado la utilidad de la agresión para la vida intraespecífica de los animales, puesto que favorece el espaciamiento territorial y el establecimiento de relaciones de jerarquía que disminuyen la frecuencia y la virulencia de los combates entre congéneres. Además ha descubierto los interesantes fenómenos de ceremonias "ritualizadas" de apaciguamiento en algunas especies. Su prédica de que el hombre debe reconocer su trasfondo animal para evitar las consecuencias funestas de su propensión innata a la agresión ha recibido el asenso de sus seguidores y de una parte de la opinión pública, pero también acerbas críticas de estudiosos de los problemas de la agresividad humana como el antropólogo Ashley Montagu (1981).

Algunos antropólogos no dudan de que buena parte del comportamiento social humano tiene una "base" biológica, pero no están por eso dispuestos a admitir que esté determinado por ella. La corriente antropológico-culturalista, con frecuencia, reclama atención al hecho, a su entender palmario, de que el género humano ocupa una posición nueva en lo atingente a la adaptación, como consecuencia de ciertos aspectos excepcionales en la historia de su evolución. Por consiguiente, sería precipitado decir que algunos rasgos universales en la especie humana (sobre todo en lo que concierne a la conducta social) obedezcan a una determinación natural, puesto que bien podrían deberse a las influencias ambientales o culturales. Los antropólogos aceptan que el hombre posee una amplia gama de potencialidades de base natural, pero confían en que estas potencialidades son íntegramente maleables por la influencia de la cultura. Lejos de decir que el cerebro humano fuese como una "tabla rasa" pasivamente receptora del aprendizaje, se subraya en cambio la excepcionalidad del cerebro humano que en lugar de estar confinado a producir un comportamiento biológicamente predeterminado, 166 da lugar a un comportamiento voluntario. 
Escritores como Ashley Montagu $(1969,1971)$ han alertado sobre los peligros que están implicados en la difusión de la postura agesionista-innatista; no tanto debidos a la actitud de algunos de sus founding fathers, sino a la de algunos de sus seguidores que podrían llegar a convertir estas teorías en una doctrina. Todo esto porque se teme, efectivamente, que la prelatura de la etología respecto a las cuestiones de la naturaleza humana haga que algunos tergiversen su sentido y echen a rodar argumentos de tipo racista. Por otra parte, la difusión alterada de la etología puede reforzar las concepciones del hombre como "guerrero natural" y estimular los argumentos fatalistas hacia sus posibilidades de cambio social y abrogación de la violencia. Montagu ha advertido sobre los razonamientos analógicos, las extrapolaciones, las inferencias no probatorias y los prejuicios que, según dice, pueden advertirse en la doctrina etológica cuando quiere aplicar a los seres humanos las averiguaciones acerca del comportamiento animal'

A veces se critica a la etología su incapacidad para enunciar y definir las relaciones entre la llamada "base biológica" del hombre y su capacidad para la cultura. Esta crítica pone en suspenso el potencial impacto que las disciplinas etológicas podrían tener sobre el método de las ciencias sociales. Los interrogantes que se dirigen a la etología tienen que ver con cuáles sean las relaciones precisas entre los aspectos biológicos y culturales de la naturaleza humana.

En la etología humana, como en otros distritos del saber, no se ofrecen pruebas concluyentes para las teorías, lo que hace que estas sean constantemente falsables. Lo mismo ocurre en el caso de la antropología cultural, cuyas afirmaciones son siempre revisadas. En algunos casos, como en la descripción de los orígenes biosociales del hombre, la antropología se permite unos amplios márgenes de especulación, pero también se refiere a numerosos hallazgos empíricos. Hay que decir que orienta este trabajo una preocupación concerniente a la averiguación de las posibles causas de la agresividad humana, asunto del que se

1 Ashley Montagu formula algunas preguntas sobre las averiguaciones de Konrad Lorenz en lo atinente al instinto y la agresión. En primer lugar, ¿Hasta qué punto es válida, y como puede justificarse, la tesis de que existe un instinto de agresión entre los animales inferiores?, y ¿Cómo pueden referirse los alcances de esa tesis a la conducta de los seres humanos? En opinión de Montagu, no sólo no son concluyentes los argumentos que se alegan a favor de la primera tesis, sino que, en el caso en que aquella fuese cierta, no está satisfactoriamente explicado cómo podría responderse a la segunda pregunta. Véase asimismo la opinión de Montagu respecto a las afirmaciones del agresionismo: "Tanto la determinación genética de la agresión como su practica prehistórica se han exagerado mucho...los seres humanos han vivido más altruística y pacíficamente durante la mayor parte de su historia evolutiva de lo que esos escritores pretenden hacernos creer.“ (Montagu, 1981, p.19). 
ocupan varias disciplinas con un legítimo corpus de conocimientos. Lo que conduce a la presente tematización surge del interés por estudiar las teorizaciones existentes sobre los orígenes de la agresión humana, en relación con su posible trasfondo animal, y la reflexión sobre el umbral entre la animalidad y la formación cultural. Esto, de alguna forma, aparece articulado con el debate entre las teorías del "instinto" y las que ponen el énfasis en el condicionamiento.

En el "planteamiento del problema" que formula Irenaus Eibl-Eibesfeld al comienzo de su obra Guerra y paz: una visión de la etología (1987) ensaya una defensa de la postura de Konrad Lorenz. Las tesis expuestas por Lorenz en Sobre la agresión; el pretendido mal habrían sufrido, aparentemente, el ataque de briosos detractores. Erich Fromm, por ejemplo, había apuntado que no había "nada más agradable para las personas...asustadizas e incapaces de modificar el curso de las cosas que lleva a la destrucción, que la teoría de Lorenz, que afirma que la violencia emana de nuestra naturaleza animal y nace de una pulsión irrefrenable hacia la agresión" (citado por Eibl-Eibesfeld, 1987, p. 3).

Eibl-Eibesfeld puntualiza, en primer lugar, que no es atinado decir que Lorenz creyese en una "pulsión irrefrenable" hacia la agresión y que su actitud intelectual apuntaba, no a aceptar el fenómeno de la agresión como algo ineluctable y metafísico, sino a investigar sus causas a partir de una visión "científico-natural". Dice además que Lorenz se ha despegado siempre de las reducciones del hombre a "puro animal". Lorenz (1971) afirmaba, en efecto, que no había nadie más capacitado para comprender la originalidad de los actos humanos que aquel que los veía surgir de su "trasfondo" - común con los animales superiores- de pautas de actuación y reconocía que el hombre había recibido la capacidad intelectual, el lenguaje y la reflexión moral como capacidades que modificaban sustancialmente su conducta.

Eibl-Eibesfeld (1987) considera al hombre como un ser natural rápidamente adaptable a los cambios en las condiciones vitales: "gracias a la ayuda de distintas adaptaciones culturales, el hombre ha desarrollado estrategias de supervivencia dentro de los espacios vitales más diversos, que a su vez implican también adaptaciones a la conducta social" (p. 4). A pesar del énfasis de Lorenz en la originalidad de la conducta ritualizada culturalmente, la condición de "ser cultural" del ser humano no debe llevar al error de subvalorar el papel de lo innato. Eibl-Eibesfeld se plantea, en sentido amplio, la pregunta acerca de si los factores hereditarios determinan la agresividad animal y humana y de hacerlo, en qué forma. Será de provecho examinar, en primera instancia, sus aclaraciones acerca de los fundamentos de la etología, para 168 avanzar en lo que atañe al estudio de la agresividad. 
Según Eibl-Eibesfeld los malentendidos acerca de la etología humana se basan en una comprensión insuficiente de los conceptos de instinto, herencia y adaptación; y la referencia a extrapolaciones abusivas del animal al hombre denota una falta de familiaridad con los métodos de la biología comparada. La etología tiene la finalidad de investigar los fundamentos causales de una conducta, es decir, el preguntar por qué un ser vivo se comporta de una manera concreta, lo que involucra los mecanismos fisiológicos, los estímulos desencadenadores, la evolución y el valor de selección de aquella conducta. El estudiar el comportamiento humano desde la perspectiva etológica conlleva una "óptica funcional, filogenético y evolutiva" y "fisiológico-causal".

Se supone que el hombre está provisto de coordinaciones hereditarias y disposiciones innatas para el aprendizaje. Estas disposiciones alcanzan a estructurar, admite Eibl-Eibesfeld, las formaciones culturales, ya que "la investigación comparada de rituales en distintas culturas demuestra...que, pese a la enorme variabilidad del fenotipo externo, en el fondo subyace una disposición estructural básicamente idéntica" y existen "leyes funcionales aplicables a la estructuración de rituales filogenéticos y culturales, ya que en el terreno creativo actúan los mismos impulsos de selección" (1987, p. 10).

En lo que concierne al comportamiento del hombre, se supone que hay gestos expresivos que pueden tomarse como "coordinaciones hereditarias", además de reaccionar a estímulos que tienden a la conservación de la especie sin que sucedan al adiestramiento. El papel de lo innato en el comportamiento humano aparece, no obstante, frecuentemente subvalorado. Se argumenta que lo residuos de comportamiento determinado filogenéticamente son rudimentarios y escasamente adaptativos. Eibl-Eibesfeld (1987) considera injusta semejante subvaloración y resalta, por ejemplo, el carácter pre-programado de la mímica humana. La misma plasticidad de la conducta humana estaría definida por una "superposición" de conductas innatas que varían en cuanto a su intensidad. Una expresión particular puede resultar de la combinación de movimientos antitéticos que son pautas conductuales innatas. De modo que nuestro comportamiento social estaría, en el fondo, determinado por adaptaciones filogenéticas: "Existen estrategias elementales de interacción, observables en todas las culturas. Sólo existe un número limitado de posibilidades para conseguir ofrecer a los otros las facetas positivas de nuestra personalidad, para entablar un contacto amistoso, para bloquear una agresión, para desafiar o apaciguar a un compañero" (p. 19). Las formas de presentación, en las diversas culturas ostentan rasgos de agresividad como de apaciguamiento, que son intercambiables por otros de igual 
signo en tanto "equivalentes funcionales". Así, resulta que un sistema universal de normas ejerce el control de las interacciones sociales; es algo parecido a una "gramática universal" de la conducta.

Para Eibl-Eibesfeld, son falsas las críticas a los métodos de Lorenz formuladas por autores como Schmidt-Mumendey y Hollitscher. Si las críticas se refieren a las "analogías" entre el comportamiento animal y la sicología humana, Eibl-Eibesfeld subraya la importancia de la investigación analógica a la hora de obtener información sobre leyes funcionales. Por lo tanto, su interés reside en estudiar las determinaciones filogenéticas de la conducta humana, comparando tanto el comportamiento del animal con el del hombre, como el carácter de las diversas culturas humanas. Para Eibl-Eibesfeld, "el ser humano prosigue la evolución biológica con la cultural. Las regularidades funcionales, conforme a las cuales desarrolla las adaptaciones culturales, son, por lo general...idénticas en la evolución biológica y la cultural” (p. 22).

La llamada "etología humana" es criticada porque se piensa que la adaptación convergente, en el caso de hombres y animales, se debe a causas diferentes: respectivamente la evolución cultural y la biológica. Luego, todo su fundamento reside en la homología. De todas formas Eibl-Eibesfeld observa que la investigación de las homologías ofrece información sobre la herencia común a un grupo y de esa forma indica de que potencial se dispone. Además, permite reconstruir series evolutivas filogenéticas.

Mientras que durante cierto tiempo imperó la idea de que la conducta humana era modelada por la cultura, a partir de las investigaciones de Lorenz comenzaron a escudriñarse los...

"determinantes filogenéticos de la conducta humana". La investigación etológica no implica desconocer las profundas diferencias entre el hombre y los otros mamíferos. Al contrario, el más detenido escrutinio de la conducta animal resalta los aspectos singulares de la conducta humana: "El hombre se caracteriza por el lenguaje y la cultura acumulativa, rasgos de los que apenas existen escasos balbuceos en nuestros parientes más próximos" (EiblEibesfeld, 1987, p. 24).

De hecho, entre todas las especies animales, la humana se destaca por acogerse al principio de evolución cultural, que le permite transmitir conocimientos a través de las generaciones. Este "mecanismo" posibilita al hombre adaptarse más rápido a condiciones vitales diversas. Los procesos de endoculturación (o seudoespeciación) aseguran la supervivencia de los grupos. En la 
transmisión de los valores culturales, es preciso que haya fuerzas que tiendan tanto a la conservación como al progreso. Una ruptura abrupta con la tradición pondría en peligro la futura existencia de la cultura, y conversamente, las culturas conservadoras en exceso se arriesgan a sucumbir al rivalizar con otras culturas. Puede que los elementos conservadores tengan que ver con "experiencias tradicionales eficaces" con las que no se quiere romper y que brindan una sensación de seguridad.

Para Eibl-Eibesfeld, "los paralelismos entre los rituales culturales y filogenéticos son sorprendentes: Funcionan como señales de comunicación, y en principio se basan siempre en los mismos requisitos. Una señal tiene que ser lo más sencilla y al mismo tiempo lo más unívoca posible" (p. 28). En los hombres, como en los mamíferos superiores, tales señales desencadenan reacciones de amistad como de repulsa. Hay, por ejemplo, señales amistosas basadas en actos de alimentación o en apelaciones infantiles al cuidado. En la cultura se observan, asimismo, rituales de salutación o regalo que se consideran tributarias de formas de comportamiento de los mamíferos. Otro tanto puede advertirse en los rituales de canto y baile que sirven para robustecer los vínculos de grupo y los de instigación y sumisión.

Entre las varias definiciones de agresión que se han formulado, todas atendibles, se destaca la observación de que la intencionalidad es un rasgo primordial de la agresión humana. Sin embargo, la amenaza y la instigación como expresiones integradas a la conducta agresiva constituyen acciones de ataque ritualizadas. La coincidencia en la fluctuación de los valores umbral es una prueba de que la agresión y la amenaza responden a un sistema fisiológico común, por lo que sería injustificado considerar como conducta agresiva sólo al enfrentamiento físico. Eibl-Eibesfeld incluye en el comportamiento agresivo conductas que tienen como consecuencia el espaciamiento territorial o la dominación, como ser amenazas y ceremoniales que no requieren el contacto físico. Por otra parte, el distingo entre agresión afectiva y agresión de captura, o bien entre agresión interespecífica e intraespecífica, es de la mayor importancia.

Muchas veces se han querido trazar relaciones entre la agresividad y la iniciativa, sin embargo, no ha podido probarse, dice Eibl-Eibesfeld, que a una mayor agresividad acompañen índices superiores de rendimiento de algún tipo, aunque pueda pensarse que, en cuanto a la personalidad global, "las personas potencialmente más agresivas en general evidencian también más capacidad de iniciativa" (p. 39). 
Los animales que intervienen en luchas intraespecíficas no procuran, por lo general, la aniquilación del congénere: muchos mamíferos disponen de mecanismos de disminución de la agresividad hacia miembros de su especie, y otros, hacia los de su grupo, puesto que controlan la agresividad frente a los miembros de su propio grupo, pero carecen de inhibiciones frente a congéneres ajenos al grupo En este caso, dice Eibl-Eibesfeld, se dan condiciones que se comparan con los procesos de "seudoespeciación" en el hombre. Hay animales que disponen de "armas" peligrosas, pero luchan con sus congéneres en "torneos" en los cuales no las emplean para dañar al adversario. La existencia de tales torneos y reacciones de sumisión deja inferir que hay algún tipo de ventaja en evitar que los animales de la misma especie se maten entre sí. De modo que puede haber una presión de selección en la evolución de los rituales de amenaza y las reglas de una lucha limitada.

Eibl-Eibesfeld habla seguidamente de las adaptaciones filogenéticas y su relación con el comportamiento agresivo. En su opinión, no es apropiado preguntarse acerca de si la agresión es "innata" o "adquirida" puesto que en la formación de conductas complejas intervienen la herencia y el medio. En cambio, las preguntas de rigor serían: “¿Existen las adaptaciones como coordinaciones hereditarias, estímulos y mecanismos desencadenantes?” y “QQué papel desempeña la experiencia individual en la integración de los componentes innatos diversos en un todo funcional?” (p. 51). Eibl-Eibesfeld, apoyándose en Freeman, acepta que "la aportación de la herencia y del medio ambiente es, desde luego, investigable" (p. 51). Este autor sostiene que

El concepto de instinto de agresión ha sido objeto de incesantes polémicas a lo largo de los últimos años, y siempre se ha aducido, a menudo por motivos claramente ideológicos, aunque también por otras consideraciones, que la agresión es por naturaleza puramente reactiva. Wickler, por ejemplo, manifiesta que, a pesar de que la agresión reporta algunas ventajas para el individuo animal, 'le perjudicaría sentir espontáneamente la apetencia de lucha tras un largo período sin perturbación alguna y marchar a molestar a otros' (Eibl-Eibesfeld, 1987, p. 61).

Eibl-Eibesfeld mantiene que la agresividad en el hombre es una "vieja herencia de los primates", aún cuando reconoce que esta posición ha recibido fuertes impugnaciones. Según dice: "los defensores a ultranza del ambientalismo afirman que la agresividad humana es única y exclusivamente un resultado de las condiciones sociales" (p. 85). Sobre tal expediente, Eibl-Eibesfeld no tarda en emitir su opinión: "yo no pongo en duda la extraordinaria importancia de las 
condiciones sociales en orden a la formación del hombre, sobre todo en lo relativo a su actitud frente a la agresión, pero las teorías que conceden escasa relevancia a la herencia como factor determinante me parecen limitadas y parciales" (p. 85). Aduce asimismo que la renuencia común a aceptar la determinación biológica se basa en un injustificado miedo al fatalismo.

La amplia variedad de formas de agresión intragrupal tiene un elemento común, cual es la presión ejercida sobre un congénere para provocar su expulsión o su sometimiento a la autoridad o las normas grupales. Una de esas formas se relaciona con los hábitos locativos, ocupación de lugares espaciales, distancia frente a los congéneres y restricción del contacto corporal, vinculadas con la formación de un sistema seguro y estable de relaciones. La lucha por los objetos, evidente en los niños de corta edad, permite observar fenómenos de agresión y de inhibición, probablemente innatos, así como las tendencias a la rivalidad y la cooperación. Hay formas de ataque que desencadenan comportamientos de ayuda. Al decir de Eibl-Eibesfeld, "hay algo reflejo, irreflexivo, en esta entrada en acción espontánea a favor de personas cercanas a nosotros, que invita a reivindicar pautas de comportamiento innatas." (p. 91).

La agresión puede tener finalidades exploratorias, de acuerdo con las cuales el agente "tantea" las posibilidades que tiene de que se vean satisfechas sus demandas. La concesión de las exigencias presentadas frecuentemente no aplaca la agresión, sino que predispone al agresor a medir de nuevo sus fuerzas. A pesar de sus dificultades, ese tipo de agresión es un factor de movilización del avance cultural. La agresión de tipo "moralista", por otra parte, surge para defenderse de los que quieren aprovecharse aviesamente de un sistema de relaciones altruistas: las formas de impartir conductas esperadas se refleja también en la agresión pedagógica, que incluye frecuentemente el castigo. Esto tiene relación con los tipos de agresión punitiva contra los que se apartan de la norma social, y cuyo comportamiento deja de ser previsible. Eibl-Eibesfeld piensa que "dado que entre los chimpancés se han observado comportamientos análogos...hay que concluir que se trata de una vieja herencia" (p. 98). La actitud de hostilidad ante lo diferente acontece de acuerdo con pautas universales, reflejadas, por ejemplo, en la burla y la risa, ya que en el reino animal, a partir de una reorientación de comportamientos de amenaza han surgido por analogía funcional ceremonias amistosas de salutación. La risa, luego, podría obrar como un mecanismo de alivio de la tensión.

El hombre está predispuesto a encuadrarse en un sistema jerárquico y a imitar las acciones de quienes tienen jerarquía más elevada. La disposición a doble- 
garse evita las constantes luchas por la supremacía. Eibl-Eibesfeld advierte que en el curso de evolución "del mono al hombre" (sic) no es posible que el hombre se haya despojado de los imperativos funcionales que lo mueven a aceptar la jerarquía, por lo tanto, no se comprende como lo innato puede haber sido sustituido completamente por la adaptación cultural. Habría, luego, una disposición innata a la obediencia.

Respecto a la lucha ritualizada, se dice que la invención de implementos que pueden servir como armas ha convertido al hombre en un "asesino pasional" en la medida en que es capaz de matar a un congénere impulsivamente. EiblEibesfeld afirma que "como adaptación cultural a esta capacidad, el hombre ha inventado reglas para utilizar las armas, sobre todo por lo que se refiere a los duelos entre hombres. Así, las armas se usan de manera que la probabilidad de matar al contrincante sea mínima" (p. 104). Para que los controles culturales tengan vigencia, es preciso que los agentes comprendan las reglas y estén vinculados entre sí: tales controles fallan cuando los grupos humanos erigen "barreras comunicativas".

En el caso de la agresión verbalizada, puede afirmarse que hay insultos que trascienden las diversas culturas. Existen, incluso, formas estereotipadas de enunciación que pueden incitar a la agresión o inhibirla. El lenguaje, luego, habría evolucionado como forma de ritualización de la lucha. Hay, además, culturas que emplean para esos fines el canto satírico.

Otras formas de conjurar la agresión son las conductas de salutación y las festividades. Mientras el saludo coadyuva a "lubricar el engranaje" de la cotidianidad social, en las fiestas los vínculos se estrechan gracias a la alimentación, al intercambio de regalos, y la actitud apaciguadora e interesada por el otro. Las bromas sirven asimismo como "costumbres-válvula" que descargan la tensión bajo formas de conducta consentidas socialmente. Otras expresiones de este mismo tipo de descarga se encuentran en los concursos y torneos deportivos, como el fútbol, y en las fiestas tradicionales, como el carnaval, en que las personas comunes agreden con befas a los de mayor jerarquía y desahogan su odio contenido.

Entre los estímulos desencadenantes de la conducta agresiva del hombre se cuenta el dolor físico y la frustración. Eibl-Eibesfeld cree que hay que añadir a estos los "estereotipos situacionales" que explica diciendo: "se cree que hay detectores (mecanismos desencadenantes innatos) sintonizados con determinadas situaciones, que se caracterizan por unas relaciones personales concretas y un de-

174 sarrollo estereotipado" (p. 114). Esto puede verse, aparentemente, en las reacciones 
frente a personas desconocidas cuya apariencia exterior es extraña; lo que puede trasladarse a las relaciones entre culturas, puesto que hay una "tendencia humana a constituir grupos cerrados y a reaccionar agresivamente frente a los forasteros que se introducen en el grupo" (p. 115) Por eso, cuando no hay vínculos comunales entre los grupos, la guerra es el estado normal de las relaciones. Eibl-Eibesfeld compara los comportamientos motrices de instigación en los chimpancés y en el hombre y concluye que presentan una gran similitud. Tal similitud se evidencia en las estrategias de agrandamiento corporal a través de las vestimentas y atavíos. Empero, también pueden contarse algunas formas específicamente humanas de amenaza, verbigracia, la mirada fija y el ceño fruncido.

Sobre la cuestión del carácter innato de la agresividad humana, Eibl-Eibesfeld se pregunta y se responde: “¿Existe un instinto de agresión y en consecuencia una apetencia de enfrentamiento agresivo que puede ser desahogada? La respuesta es afirmativa. Muchas personas están motivadas para actuar agresivamente. Buscan los enfrentamientos, y utilizan con profusión todas las posibilidades para desplegar su agresividad en forma ritualizada" (p. 117). La agresividad es pasible de ser desplegada o liberada a través de comportamientos agresivos directos y vicarios: por ejemplo, la visión de filmaciones de contenido violento. También el humor o la risa se supone que aminoran la agresión, pero probablemente no a través de una descarga, sino de una orientación debida al estímulo de emociones que frenan la agresividad.

Para Eibl-Eibesfeld, la discusión ha dejado de centrarse en la existencia de un "instinto de agresión" (que hay que dar por supuesto) para atender al problema de si el comportamiento agonístico se adquiere en la época juvenil de aprendizaje (tesis del instinto secundario) o es innata al ser humano (tesis de la pulsión primaria). Según dice, no existen pruebas concluyentes de la existencia de una pulsión de agresión primaria, pero una serie de indicios abogan por su admisión. Un autor llamado A. Plack ha sugerido que si hubiese una satisfacción plena de los instintos, no habría agresión, pero Eibl-Eibesfeld arguye que el que cualquier frustración sea capaz de activar la agresividad, no implica que sea su única causa.

Eibl-Eibesfeld postula la existencia de "ataques espontáneos de ira de origen neurógeno, que van acompañados por una actividad eléctrica característica en ciertas regiones cerebrales” (p. 123), lo que lleva a creer que la agresión está referida a la actividad de ciertos centros neurales.

La conducta agresiva de los animales está fuertemente influida por la maduración y el aprendizaje. En el hombre, esta influencia se ve muy incrementada, a 
partir de los premios y castigos y los ideales del éxito vigentes en el modelo social. En pueblos amantes de la guerra se enseña a los niños a responder a la agresión. Los niños waika, por ejemplo, se identifican con la conducta de sus mayores emulando sus alardes e intercambios de golpes. En las culturas de ideales pacíficos (por ejemplo, los bosquimanos), no se induce a los niños a que contesten a los ataques, sino que se los calma, y se disuaden las peleas por la intervención de un niño de más edad. Todo esto indica que en la conformación del comportamiento agresivo en una formación cultural, el aprendizaje del éxito juega un papel muy pregnante. Se acepta entonces que "la agresividad humana está determinada en gran medida por las experiencias individuales: jamás los etólogos han puesto en duda la validez de este aserto" (Eibl-Eibesfeld, 1987, p. 127).

\section{Metodología}

Se ha procurado examinar los argumentos en virtud de los puntos de concordia que pueden advertirse entre dos posiciones pretendidamente antagónicas. La tarea emprendida ha consistido en evaluar un intento de explicación del fenómeno de la agresividad humana, conceptualizada a partir de criterios funcionales. Se trató de reconstruir los argumentos de la etología humana, para después, contrastarlos con los esgrimidos por cierta tendencia predominante en la antropología cultural. Por un lado, esto tiene el resultado no despreciable de ofrecer unas bases más precisas para una definición de la agresión y una explicación consistente de sus causas. Por otro, la explicitación de esos elementos comunes tiene una importancia singular a la hora de pensar en cuáles serían las condiciones óptimas para una minimización de la conflictividad social.

\section{Resultados}

Eibl-Eibesfeld sostiene, en general, que hay preceptos innatos al hombre que le prescriben "no matar" a los de su propia especie, pero que pueden neutralizarse o disfrazarse apelando a "filtros normativos culturales". Esto ocurre, por ejemplo, cuando se niega a los extraños la condición humana, o se evaden responsabilidades alegando formas adquiridas de fidelidad u obediencia. A los efectos de esas racionalizaciones y justificaciones, se manipulan "estereotipos" relacionados con la patria, la igualdad y la libertad. Así, la acción de matar envuelve al hombre en un conflicto de normas, entre el filtro normativo biológico, que previene no matar, y el filtro normativo cultural, que tiende a sofocarlo. Esto explana los remordimientos y cargos de conciencia que experimentan los matadores en las más diversas culturas. Eibl-Eibesfeld (1987) explica que: 
Cuando un filtro normativo cultural se imbrica o se superpone a otro biológico, generando un conflicto entre ambos, el hombre experimenta esa discordancia y suscita en él una impresión de desagrado. Dado que lo innato es más sólido y opone mayor resistencia que lo adquirido a la modificabilidad, se origina una presión que exige la armonización de ambos filtros normati$\operatorname{vos}($ p. 206).

Se puede obedecer una orden cultural de matar, pero no se puede dejar de sentir el peso de la conciencia: "si algún día...se consigue la paz mundial, será porque lo se ha deseado viva y espontáneamente atendiendo no única y exclusivamente a consideraciones basadas en la racionalidad y en el pragmatismo, sino a otros factores más poderosos: las normas que son innatas (p. 206).

La norma que prescribe no matar es innata, y por lo tanto, se adhiere a ella naturalmente, aunque también se da el caso de que la guerra entre congéneres es inconveniente desde el punto de vista racional. Los contactos entre seres humanos, y la consecuente persuasión de que los extraños son congéneres, crean una conciencia de especie que inhibirá progresivamente la agresión, puesto que los seres humanos, más allá de la variación cultural, poseen "un repertorio de comportamientos innatos idénticos hasta el más mínimo detalle", de suerte que "desde el punto de vista de la biología del comportamiento, la humana es una especie, y en consecuencia posee una base referencial común que permite encontrarse y entenderse. Únicamente desde el plano cultural definimos a los otros como no-humanos y ya no podemos hacerlo con la conciencia tranquila" (EiblEibesfeld, 1987, p. 206). Asimismo, los "múltiples contactos" transculturales tienden a crear una conciencia del hombre como especie.

El conflicto entre las normas, que oscila entre la agresión y el apaciguamiento, la compasión y la intolerancia, no tiene una resolución invariable. La jerarquización entre las normas parece obedecer en cada caso a una construcción cultural. Una norma "cultural" de conservación de la especie, tal como lo postula Eibl-Eibesfeld, ocuparía en cambio una jerarquía mayor que la de las "normas culturalmente relativas". Una evolución cultural bajo el imperio de la razón "seguiría las mismas reglas que la biológica, pasaría por el mecanismo de la mutación y de la selección. La selección pondría también a prueba la contribución de una evolución cultural no dirigida por la razón a la conservación de la especie", aspecto de importancia ya que "la elección considera un 'error' todo lo que no da buen resultado y, por tanto, lo elimina: muchas especies han pagado este 'error' con su desaparición. Una evolución gobernada por la razón puede preservarnos de tales errores." (Eibl-Eibesfeld, 1987, p. 208). La intolerancia respecto al extra- 
ño ha dejado de ser adaptativamente conveniente; al contrario, sería aconsejable fomentar la actitud pacífica: "con la ayuda de este conocimiento de causa y apoyados en nuestras inhibiciones biológicas de la agresión, se está en disposición de controlar con eficacia la reacción frente al 'extraño'. Cuando se suscita un conflicto entre dos normas biológicas -que el hombre vivencia bajo la forma de intolerancia y compasión-, el conocimiento causal contribuye a hacer prevalecer la última" (1987, p. 208). La supervivencia es, en esta línea, la base de cualquier conducta, al nivel de una cultura, una raza o toda la humanidad. La conducta humana está regida por pautas de comportamiento innatas que comprenden a toda la especie: por consiguiente, la meta ha de ser la conservación de la humanidad. Una evolución comandada por la razón debería contemplar la multiplicidad de culturas, que se supone deseable a los fines evolutivos, y tolerar sistemas de valores diferentes en la medida en que no infrinjan las normas que previenen la supervivencia de la especie.

En relación con los rituales para la preservación de la paz, que incluyen fiestas e intercambio ceremonial de bienes, Eibl-Eibesfeld destaca que "en numerosas culturas la conclusión del conflicto y la preservación de la paz se efectúa a través de rituales (fiestas) obligatorias, que, en sus líneas básicas, obedecen al mismo modelo” (1987, p. 231). En todos los estadíos de civilización el hombre ha tratado de encontrar modos incruentos de resolver los enfrentamientos, los cuales han debido actualizarse con arreglo a los adelantos tecnológicos y sociales. Eibl-Eibesfeld sostiene que el camino de la ritualización conduce a un apaciguamiento de las pugnas intergrupales, no obstante "sigue sin solucionarse el conflicto funcional entre agresión y vinculación amistosa" (p. 234). Las ritualizaciones, en ese caso, no han logrado la misma eficacia que en el vínculo intragrupal, en el que operan pautas de comportamiento filogenéticas y culturales. El hombre tiene, luego, la iniciativa de llevar este mismo tipo de pautas a la esfera intergrupal presumiendo que así podrá inhibir los conflictos. Se sabe que en la agresión interespecífica, los ataques suelen ser mortales y ocurren una vez que se ha sobrepasado una distancia crítica. En el conflicto intraespecífico no pasa lo mismo: los conflictos intragrupales no persiguen el daño. De modo que el trato con miembros de grupos extraños puede ser más hostil que con los del propio.

Eibl-Eibesfeld reconoce una serie de formas de evitación de los conflictos destructivos que son comunes a los animales y al hombre, verbigracia: instigaciones, actitudes de sumisión, intervención de terceros para concluir la disputa, formación de jerarquías sociales, pautas de contacto amistoso, desarrollo de normas y cut off, evitación o evasión del conflicto. No obstante, existen también 178 algunas formas de evasión que parecen ser exclusivas del hombre, como las 
costumbres-válvula para desahogan la agresividad, los vínculos matrimoniales que permiten integrar grupos separados, las posibilidades de contacto entre facciones enemigas y el despertar de la conciencia humanitaria y la educación para la paz que rechaza conscientemente los modelos agresivos. Las formas compartidas por el animal y el hombre "adquieren su dimensión específicamente humana en el fenómeno de la ritualización cultural, por ejemplo, mediante la verbalización. Esto es aplicable tanto a las luchas ritualizadas como a esa afinidad de costumbres que fortalecen un vínculo, disminuyen tensiones, fomentan la solidaridad de los miembros del grupo, mantienen abiertos los canales de comunicación entre los enemistados y finalmente reconcilian a los bandos contendientes mediante la firma de la paz" (Eibl-Eibesfeld, 1987, p. 239).

A criterio de Eibl-Eibesfeld, hay en la conducta humana dos "filtros de normas" que ordenan procedimientos opuestos y por ello entran en conflicto: "si percibimos al enemigo a distancia, tendemos a matarlo por considerarlo enemigo de acuerdo con el filtro de normas culturales. Pero apenas establecemos un contacto personal, nuestras inhibiciones innatas de la agresión se ponen en marcha; más aún: se activan las pautas de comportamiento de toma de contacto amistoso" (p. 241). Hay escritores que han afirmado que el hombre teme a la paz, en lugar de perseguirla, siente como un peso el no poder exteriorizar su agresión y declama a favor de la paz insinceramente. Eibl-Eibesfeld dice: "es verdad que un miedo basado en la desconfianza ha impedido hasta la fecha un desarme generalizado, pero este hecho no demuestra que el hombre no desee la paz." (p. 242).

Konrad Lorenz pensaba que la "estructura motivacional humana" no estaba preparada para la convivencia pacífica en sociedades de millones de individuos. El corazón del hombre no puede habituarse a amar a un sinnúmero de semejantes: en este sentido, el ser humano es un eslabón perdido que no es capaz de satisfacer las demandas de la vida social moderna. Eibl-Eibesfeld, por el contrario, considera que el ser humano es "bastante bueno", puesto que ha podido adaptarse a las sociedades de masas en forma relativamente satisfactoria. La creación y fortalecimiento de vínculos se han basado en la herencia filogenética, que fundamenta el mandamiento religioso de amor al prójimo. Además, apunta que a pesar del temor al extraño, el hombre intenta relacionarse con los otros hombres y considerarlos sus hermanos, identificándose con ellos a través de una "poderosa carga emocional"...los hombres se han unido para luchar juntos contra las fuerzas de la naturaleza tanto como para combatir a los 'enemigos'. De hecho hay una gran cantidad de tareas que 
unen a la humanidad, y en el futuro no escasearán los desafíos de este tipo" (Eibl-Eibesfeld, 1987, p. 243). Eibl-Eibesfeld está a favor de las tesis de que el hombre tiende a propagar su simpatía hacia todos sus semejantes y de que esta simpatía proviene de una ampliación del ethos familiar. Así resulta que nuestra estructura motivacional capacita para la paz.

Una educación que fomente la actividad creadora como modo de sublimar la agresividad y que disminuya las represiones, podría ser un planteo de interés. Eibl-Eibesfeld cree, no obstante, que si se priva a los niños de las debidas directrices y controles culturales, se convierten en personas inseguras, que usarán la agresividad como método de exploración social. Las contumelias contra la familia son asimismo algo peligroso, pues la familia es el lugar de desarrollo de la capacidad de amar y si se priva al individuo de los vínculos referenciales que ella proporciona, podrá tener más adelante graves problemas de relación.

Las propuestas terapéuticas de reprimir la agresividad a partir de la reeducación, las drogas o las intervenciones quirúrgicas entrañan a su vez grave peligro, porque en el fondo, no se sabe si la supresión total de la agresividad sería algo deseable. Las personas agresivas pueden realizar acciones positivas para la superación de problemas y no necesariamente dedicarse a la agresión destructiva. Se supone que un hombre sin agresividad no podría hacer algún progreso en el orden intelectual o social: las soluciones propuestas por la terapéutica podrían ser apropiadas para casos de agresividad patológica.

Habría que procurar, luego, formas de educación que no borren por completo la agresividad, sino que la redirijan y socialicen, mitigando sus efectos destructivos. Eibl-Eibesfeld piensa que los individuos jóvenes deben ser expuestos a experiencias de agresión para que conozcan sus efectos. La educación no sólo debe apuntar al autocontrol, sino también a formar conciencia acerca de la tolerancia y la solidaridad que se deben a cualquier ser humano, a una actitud de comprensión de otros sistemas culturales y a una valoración de la diversidad. Para eso, es preciso derribar las barreras comunicativas que contribuyen a estigmatizar a los extranjeros como la "encarnación del mal."

Existen una serie de comportamientos innatos de vinculación y apaciguamiento que sirven para controlar la agresión, a pesar de que la importancia de esos rituales culturales no está suficientemente reconocida. Así, la paz es algo que está al alcance del hombre, y que este busca siguiendo sus inclinaciones. El deseo de paz debe conducir a ideas conniventes con la coopera- 
ción a nivel mundial. Eibl-Eibesfeld propone delegar en las organizaciones internacionales dedicadas a la paz la capacidad de administrar justicia y dirimir las querellas.

A pesar de que estudiosos del comportamiento han pretendido advertir en algunos animales un egoísmo muy acusado, Eibl-Eibesfeld advierte que "también en el reino animal vemos que se desarrollan otras pautas de comportamiento que impiden los enfrentamientos destructivos intraespecíficos, sin duda en beneficio mutuo y con toda seguridad sobre la base de la reciprocidad" (p. 256). Los comportamientos humanos no obedecen, según Eibl-Eibesfeld, a los supuestos beneficios que podrían reportar a la continuidad en el tiempo de la dotación hereditaria, como proponen algunas teorías, sino al asentimiento a valores que son de importancia para el hombre: "sentimos sensaciones agradables cuando somos amables con nuestros hijos o con nuestros semejantes, mostramos compasión y tendemos a comportarnos de manera altruista" (p. 256). La selección ha actuado sobre el grupo consanguíneo en el período de la filogénesis o desarrollo de la especie, con la emergencia de las señales de comunicación madre-hijo. Esas señales sirvieron a su tiempo para favorecer la comunicación entre adultos. En el caso de los seres humanos, ese ethos familiar es oportunamente transferido a un grupo de pertenencia más amplio: "aprovechando esta disposición innata del hombre para la vinculación individual, el adoctrinamiento ideológico cultural tiene a cohesionar al grupo como si fuera una familia, es decir, propicia el desarrollo de un ethos grupal familiar que sitúa los valores del grupo por encima del valor de la estirpe y de la familia" (p. 257). Eibl-Eibesfeld advierte entonces que es un indudable progreso la sustitución del egocentrismo por el interés grupal, aunque resta todavía saber si podrá superarse la esfera de las luchas intergrupales. Un humanitarismo que tendiese a menguar la vigencia de tales luchas no requeriría el desmantelamiento de la propia identidad cultural -que, como se ha visto, sería contraproducente para el vigor de la cultura humana en general- si bien tiene como requisito indispensable el respeto y la valoración de los otros: "la capacidad para la solidaridad y la simpatía, nacidas en el cohesionado grupo pequeño, y la aptitud cultural de tratar como hermanos a personas desconocidas, favorecen la adhesión a la humanidad que trasciende las fronteras grupales" (Eibl-Eibesfeld, 1987, p. 257). En suma, puede decirse que el ser humano tiene predisposiciones tanto para la guerra como para la paz, y debería asumir con respecto a ello una elección racional y responsable. 
Mientras que la agresión intragrupal humana está, en buena medida, basada en adaptaciones filogenéticas que la controlan, la agresión intergrupal persigue la aniquilación del contrincante como resultado aparente de los procesos de endoculturación o "seudoespeciación" que han diferenciado los grupos humanos. Los seres humanos tienen disposiciones innatas a establecer vínculos, que son reprimidas con la formación de grupos rígidos que comienzan a competir entre sí por el espacio y los recursos naturales. La agresividad destructiva del hombre está marcada por una superposición de filtros culturales que ordenan al hombre desligarse de sus obligaciones de amar al prójimo, las cuales estaban presentes en sus filtros biológicos. Esto produce en él problemas de conciencia puesto que, en medio de la disputa, percibe al contrario como un semejante. Eibl-Eibesfeld dice que "en esta antinomia entre la norma cultural y la biológica radica el anhelo de paz universal del hombre, que desea armonizar el filtro normativo cultural y el biológico" y añade que "la única esperanza la constituye nuestra conciencia, y a partir de ella podríamos conseguir la paz sometiendo la evolución a los dictados de la razón" (Eibl-Eibesfeld, 1987, p. 260). Esto implica que hay que proponerse el ejercer de manera incruenta las funcionalidades de la guerra y educar para la convivencia pacífica, la tolerancia y la comprensión.

\section{Conclusiones}

El trabajo se proponía evaluar críticamente los argumentos que ofrecen los autores en lo atingente a los orígenes de la agresividad humana, tanto como las posibilidades de proponer puntos en común que propendan a la búsqueda de nuevas formas de abrogación de la conflictividad social El contacto con la literatura ha reportado observaciones interesantes, y también incluso algunas afirmaciones que merecen ser estudiadas, entre las que se cuenta la siguiente: de la relación comparativa entre las tesis de la etología humana y la antropología cultural, resulta la saturación de dos enunciados: primero, el de que el hombre no es un ser naturalmente inclinado a la agresión intraespecífica, y segundo, el de que el ambiente tiene un rol preponderante en el incentivo o control de la conducta agresiva. Esta conclusión se ilustra en el cuadro siguiente.

Las de la izquierda son aseveraciones típicas de la etología humana en la versión de Eibl-Eibesfeld. En el límite entre ellas, podría consignarse la tesis según la cual la adquisición de elementos técnicos ha incrementado el potencial agresivo de la especie humana descompensando el equilibrio agresión-inhibición . En

182 efecto, los elementos técnicos no dejan de ser parte del ambiente y su influencia 


\begin{tabular}{|l|l|l|}
\hline \multicolumn{1}{|c|}{ Etología Humana } & \multicolumn{1}{|c|}{ Antropología Cultural } & \multicolumn{1}{c|}{ Resultado } \\
\hline $\begin{array}{l}\text { El hombre posee unas } \\
\text { potencialidades para la } \\
\text { agresividad, compensadas } \\
\text { por formas naturales de } \\
\text { inhibición. }\end{array}$ & $\begin{array}{l}\text { El hombre es un ser } \\
\text { naturalmente equipado para } \\
\text { la vida pacífica y comunitaria, } \\
\text { el amor y la cooperación. }\end{array}$ & $\begin{array}{l}\text { El hombre no está } \\
\text { naturalmente inclinado a la } \\
\text { agresión intraespecífica. }\end{array}$ \\
\hline $\begin{array}{l}\text { La modernización, el ocaso } \\
\text { de la tradición y la vida en } \\
\text { grandes conglomerados } \\
\text { llevan a los seres humanos a } \\
\text { una agresividad que sus } \\
\text { formas naturales de } \\
\text { inhibición no son capaces de } \\
\text { contrarrestar. }\end{array}$ & $\begin{array}{l}\text { La educación deficiente, la } \\
\text { vida en condiciones } \\
\text { desfavorables y la difusión de } \\
\text { ideas acerca de la agresividad } \\
\text { innata de la especie humana, } \\
\text { predisponen al hombre a ser } \\
\text { agresivo }\end{array}$ & $\begin{array}{l}\text { El ambiente tiene un rol } \\
\text { preponderante en el } \\
\text { incentivo o el control de la } \\
\text { conducta agresiva. }\end{array}$ \\
\hline
\end{tabular}

en el comportamiento tiene una importancia que no se puede desconocer. En el centro, figuran expresiones que pueden atribuirse sin duda a la línea de antropólogos como Ashley Montagu. A la derecha, se encuentra la parte en la que concuerdan los dos partidos, el de los etólogos y el de los antropólogos. Así, a pesar de las disputas procedimentales en que se han enzarzado tanto la corriente de la etología humana como la de la antropología cultural, y que versaban sobre las formas de estudiar el comportamiento humano y sobre las presunciones acerca del origen cabal de esos comportamientos, se puede ver cómo algunas de sus concepciones teóricas derivan en afirmaciones compatibles entre sí, en particular en lo que se refiere a las causas, consecuencias y soluciones para el problema de la agresividad.

Desde luego, las diferencias entre estos partidos, a pesar de todo, habrán de ser prominentes, y obedecerán a concepciones distintas de lo que se entiende por "ambiente". La destrucción de un equilibrio natural no puede ser revertida por medios tan artificiales como los que la provocaron. Destruir lo natural y suplirlo con lo artificial no deja de ser un artilugio sin ton ni son, una mueca desesperada de la cultura humana ante lo irremediable. En cambio, pensar que

\footnotetext{
1 "Muchos estudiosos y observadores de los niños han llegado a la conclusión de que la conducta agresiva se aprende. Es decir, un niño cuya conducta agresiva se ve recompensada...tiende a ser más agresivo que otro cuya conducta agresiva se vea desanimada por derrotas constantes o por desaprobación." (Montagu, 1981, p. 28). "Ninguna pauta de conducta puede explicarse mediante una sola y única condición. De hecho, suponer que una conducta tan compleja y generalizada como la "crueldad" se debe sólo a la herencia del hombre, sin contribución alguna del medio, es adoptar una posición que muy pocos científicos reputados aceptarían." (Montagu, 1981, p. 53).
} 
una reforma de la educación, una mejora en los estándares de vida y la rectificación de los discursos sobre la agresividad puede conducir a una sociedad más pacífica, apunta más bien a cierta esperanza, aunque sea mesurada, por lo que puede construirse, pero no a la nostalgia por lo que se perdió.

\section{Referencias}

Barash, D. (1987). La liebre y la tortuga: cultura, biología y naturaleza bumana. Barcelona: Salvat.

Eibl-Eibesfeld, I. (1987). Guerra y paz: una visión de la etología. Barcelona: Salvat.

Eibl-Eibesfeld, I. (1977). Amor y odio. Historia natural de las pautas elementales de comportamiento. México: Siglo XXI.

Fromm, E. (1966). El corazón del hombre. México: FCE.

Lorenz, K. (1985). Consideraciones sobre la conducta animal y humana. Barcelona: Planeta.

Lorenz, K. (1984). Los ocho pecados capitales de la humanidad civilizada. Barcelona: Plaza y Janes.

Lorenz, K. (1971). Sobre la agresión: el pretendido mal. México: Siglo XXI.

Lorenz, K, (1966). Lucha ritualizada. En Carthy, J.D. y Ebling, E.J., Historia natural de la agresión. México: Siglo XXI.

Lorenz, K. y Leyhausen, P. (1981). Biología del comportamiento, raíces instintivas de la agresión, el miedo y la libertad. México: Siglo XXI.

Maliandi, R. (1984). Cultura y Conflicto. Buenos Aires: Biblos.

Montagu, A. (1969). Qué es el hombre. Buenos Aires: Paidós.

Montagu, A.M.F y otros (1970). Hombre y agresión. Barcelona: Kairós.

Montagu, A. (1961). La dirección del desarrollo humano. Madrid: Tecnos.

Montagu, A. (1981). La naturaleza de la agresividad humana. Madrid: Alianza.

Palacio R. (2003). La agresión y la guerra desde el punto de vista de la etología y la obra de Konrad Lorenz. Revista de Estudios Sociales, (14), 55-62. 